\title{
Qualidade pós-colheita de cenoura durante o desenvolvimento em monocultivo e consorciada com rabanete ${ }^{1}$
}

\author{
Quality carrot powder-crop during development in monoculture and associated radish
}

\author{
Rafaella Martins de Araujo Ferreira ${ }^{2 *}$, Edna Maria Mendes Aroucha ${ }^{3}$, Hélida Campos de Mesquita ${ }^{4}$, Francisco \\ Cláudio Lopes de Freitas ${ }^{5}$ e Glauber Henrique de Sousa Nunes ${ }^{5}$
}

\begin{abstract}
Resumo - O trabalho objetivou avaliar a qualidade pós-colheita de cenoura 'Brasília' durante o desenvolvimento em monocultivo e consorciada com rabanete 'Crimson Gigante'. A semeadura foi realizada sob canteiros da horta experimental da Universidade Federal Rural do Semi-Árido (UFERSA), localizada no município de Mossoró-RN. A adubação foi efetuada conforme as exigências da cultura. $\mathrm{O}$ experimento foi conduzido em delineamento de blocos casualizados, no esquema fatorial $2 \times 4$ (dois sistemas de cultivo e quatro épocas de colheita) com quatro repetições. As raízes de cenoura foram colhidas nos intervalos de 83; 91; 99 e 107 dias após a semeadura, e em seguida foram transportadas para o Laboratório de Pós-Colheita da UFERSA, onde procederam-se as seguintes análises físicas e físico-químicas das raízes: massa fresca, comprimento, diâmetro, firmeza, sólidos solúveis, potencial hidrogeniônico, acidez titulável e vitamina C. As variáveis estudadas foram submetidos à análise de variância e os níveis do fator qualitativo (sistemas de cultivo) foram comparados pelo teste de Tukey, enquanto para o fator quantitativo (épocas de colheita) procedeu-se o ajuste de modelos de regressão. O sistema de produção consorciado de cenoura e rabanete não propiciou diferença nas características avaliadas. Exceto para o diâmetro das raízes, que foi menor em cultivo consorciado. A época de colheita das raízes influenciou no diâmetro, $\mathrm{pH}$, acidez titulável e vitamina C. Com exceção do $\mathrm{pH}$, as demais características aumentaram com a época de colheita.
\end{abstract}

Palavras-chaves - Cenoura. Rabanete. Cultivo consorciado.

\begin{abstract}
The work had for objective to evaluate the quality carrot 'Brasília ' powder-crop during the development in monoculture and intercropped with radish 'Crimson Gigante '. The sowing was accomplished in stonemasons of the experimental vegetable garden of the Universidade Federal Rural do Semi-Árido (UFERSA), in Mossoró-RN. The manuring was made according to the demands of the culture. The experiment was conducted in randomized blocks, in the factorial design 2 x 4 (two cropping systems and four crop times) with four repetitions. The carrot roots were harvested in the intervals of 83, 91, 99 and 107 days after the sowing, and soon afterwards they were transported to the Postharvest Laboratory of UFERSA, where the following analyses were proceeded: fresh mass, length, diameter, firmness, soluble solids, $\mathrm{pH}$, titrabable acidity and vitamin $\mathrm{C}$. The studied variables were submitted the variance analysis, the qualitative factor (cropping systems) were compared by Tukey test and the quantitative factor (crop times) were compared by regression analysis. The associated production system of carrot and radish did not influence the characteristics assessed. Except for the diameter of the roots, that was smaller in associated system. The time of the crop, and of the roots influenced in the diameter, $\mathrm{pH}$, titrabable acidity and vitamin $\mathrm{C}$. Except for the $\mathrm{pH}$, the other characteristics increased with the crop time.
\end{abstract}

Key words - Carrot. Radish. Intercropping.

\footnotetext{
* Autor de correspondência

'Recebido para publicação em 26/03/2010; aprovado em 16/02/2011

Monografia do primeiro autor apresentada ao Curso de Engenharia Agronômica, UFERSA

${ }^{2}$ Programa de Pós-Graduação em Fitotecnia, UFERSA, BR 110, Km a e Silva, Mossoró-RN, Brasil, rafaellamarafe@gmail.com

${ }^{3}$ Departamento de Agrotecnologia e Ciências Sociais, UFERSA, Mossoró-RN, Brasil, aroucha@ufersa.edu.br

${ }^{4}$ Instituto Federal de Educação Ciência e Tecnologia do Rio Grande do Norte, Campus Apodi, Sítio Lagoa do Clementino s/n, Zona Rural, Apodi-RN, Brasil, helida_campos25@yahoo.com.br

5epartamento de Ciências Vegetais, UFERSA, BR 110, Km a e Silva, Mossoró-RN, Brasil, franciscoclaudio@ufersa.edu.br, glauber@ufersa.edu.br
} 


\section{Introdução}

Entre as hortaliças cujas partes comestíveis são as raízes, a cenoura (Daucus carota L.) é a de maior valor econômico. Esta destaca-se pelo valor nutritivo, sendo uma das principais fontes de pró-vitamina A (betacaroteno) (TEÓFILO et al., 2009).

A composição química das raízes é influenciada por fatores genéticos e condições de cultivo tais como: sistemas de cultivos, tipos e propriedades físicas do solo, época de plantio, temperatura durante a estação de crescimento da cultura (BAARDSETH et al., 1995), além da fertilização, densidades de plantio e época de colheita.

O sistema de cultivo consorciado é bastante difundido entre os produtores rurais de regiões tropicais, cujos fatores climáticos, como temperatura e radiação solar não apresentam limitações. Bezerra Neto et al. (2007) explicam que esta técnica consiste no plantio de mais de uma cultura, simultaneamente, numa mesma área de terra, durante parte ou todo o período de desenvolvimento das culturas.

O principal objetivo da consorciação nas regiões semiáridas do Brasil tem sido, maximizar a utilização dos recursos ambientais e área de plantio, além de reduzir mão-de-obra nas diversas operações como aplicação de insumos e tratos culturais (NEGREIROS et al., 2002).

Por outro lado, desvantagens podem estar associadas às culturas consorciadas, como a competição entre as espécies por nutrientes, água, luminosidade (SALGADO et al., 2006), o que pode resultar em efeitos negativos na qualidade do produto. Assim, a escolha criteriosa das culturas componentes do sistema é de fundamental importância para que se possa propiciar exploração máxima das vantagens do cultivo consorciado (GRANGEIRO et al., 2008), pois existem espécies que quando cultivadas em consorcio obtêm benefícios ou prejuízos mútuos.

O cultivo de uma espécie de ciclo curto nas entrelinhas de outra de ciclo longo permite a obtenção de duas colheitas em épocas distintas sem aparente prejuízo para as culturas. Isto foi detectado no cultivo consorciado de alface e rabanete (CECÍLIO FILHO; MAY, 2002; REZENDE et al, 2005), e de alface e cenoura (BEZERRA NETO et al, 2003; NEGREIROS et al, 2002).

A consorciação de hortaliças é bastante utilizada em todo o mundo (MONTEZANO; PEIL, 2006), porém informações sobre a qualidade das hortaliças submetidas a esse sistema de plantio são ainda incipientes. Dessa forma, este trabalho objetivou avaliar a qualidade pós-colheita de cenoura 'Brasília', durante o desenvolvimento em monocultivo e consorciada com rabanete 'Crimson Gigante'.

\section{Material e métodos}

O experimento foi conduzido na Horta Didática da Universidade Federal Rural do Semi-Árido (UFERSA) em Mossoró - RN, situada a $5^{\circ} 11^{\prime}$ de latitude Sul, $37^{\circ} 20^{\prime}$ longitude a Oeste de Greenwich e $18 \mathrm{~m}$ de altitude. O clima, segundo a classificação de Koppen é 'BSWh' (muito seco, com estação de chuva no verão atrasando-se para o outono) conforme Carmo Filho e Oliveira (1989).

O solo da área experimental foi classificado como Podzólico Vermelho-Amarelo equivalente eutrófico, segundo classificação apresentada pelo Ministério da Agricultura (BRASIL, 1971). O preparo do solo foi feito com uma aração e duas gradagens. Posteriormente, foram confeccionados canteiros com 1,20 m de largura e $20 \mathrm{~m}$ de comprimento. A adubação foi realizada com base nas recomendações técnicas para a cultura da cenoura (VIEIRA et al., 2000).

O delineamento experimental utilizado foi de blocos casualizados, em esquema fatorial $2 \times 4$, dois sistemas de cultivos (monocultivo e consorciadas) e quatro épocas de colheita da cenoura (83; 91; 99 e 107 DAS), com quatro repetições. Utilizou-se cenoura 'Brasília', adaptada para cultivo de verão e regiões com temperaturas elevadas (OLIVEIRA et al, 2004; REZENDE et al, 2005), consorciada com rabanete cultivar 'Crimson Gigante'.

A parcela experimental foi constituída por seis linhas de 1,20 m de comprimento, espaçadas em $20 \mathrm{~cm}$, tanto em monocultivo quanto consorciado (o rabanete foi semeado entre as fileiras da cenoura). Foi considerada área útil, as quatro linhas centrais de cenoura, desprezando-se $25 \mathrm{~cm}$ de cada extremidade das linhas. Foram realizados desbastes de plantas de rabanete e cenoura aos sete e trinta dias após a semeadura (DAS), respectivamente, deixando-se as plantas espaçadas a seis $\mathrm{cm}$ na linha de plantio. A irrigação foi efetuada por microaspersão, conforme as necessidades da cultura.

O rabanete foi colhido aos 30 DAS e as raízes de cenouras foram colhidas aos 83; 91; 99 e 107 DAS. Estas foram transportadas para o Laboratório de Pós-Colheita da UFERSA, onde se procederam as seguintes análises físicas e físico-químicas nas raízes: massa fresca - determinada com o auxílio de balança digital com escala em gramas e precisão de duas casas decimais; comprimento - realizado com o auxilio de régua graduada, expresso em milímetros; diâmetro - determinado com o auxilio de paquímetro graduado, expresso em milímetros; firmeza - medida com auxílio de penetrômetro (McCormick FT327) com plunger de ponteira cilíndrica de $8 \mathrm{~mm}$ de diâmetro na posição mediana das raízes, tendo os resultados obtidos em libras força (lbf) e convertidos a Newton (N) pelo fator 
de conversão 4,45; sólidos solúveis (SS) - utilizou-se refratômetro digital modelo PR-100 Palette (Attago Co. Ltd, Japan), e os resultados expressos em percentagem $(\%) ; \mathbf{p H}$ - determinado através de potenciômetro digital modelo DMPH-2 Digimed, calibrado em solução tampão de pH 4,0 e 7,0; acidez titulável - determinada através da titulação de uma alíquota de $10 \mathrm{~g}$ de polpa homogeneizada, com solução de $\mathrm{NaOH}(0,1 \mathrm{~N})$, previamente padronizada, com os resultados expressos em mEq/100g; vitamina $\mathbf{C}$ - foi realizada por titulação com DFI (2,6 diclorofenol-indofenol 0,02\%) e expresso em $\mathrm{mg}$ de ácido ascórbico por $100 \mathrm{~g}$.

Os dados foram submetidos à análise de variância. Os níveis do fator qualitativo (sistemas de cultivo) foram comparados pelo teste de Tukey ao nível de significância de $5 \%$, enquanto para o fator quantitativo (épocas de colheita) procedeu-se o ajuste de modelos de regressão. A escolha do modelo seguiu os critérios de significância e dos parâmetros do modelo, significância do desvio de regressão e estimativa do coeficiente de determinação $\left(\mathrm{R}^{2}\right)$. Foi utilizado, para as análises estatísticas, o software SAEG, versão 9.0 (SAEG, 2005).

\section{Resultados e discussão}

Observou-se interação não significativa entre sistemas de cultivo e épocas de colheita. Sendo significativo o efeito isolado de sistemas de cultivo para a característica diâmetro de raízes (TAB. 1) e efeito isolado de épocas de colheita para o diâmetro de raízes, $\mathrm{pH}$, acidez e vitamina $\mathrm{C}$ (FIG. 1).

O diâmetro das raízes foi menor quando as cenouras foram cultivadas em consórcio com o rabanete
(TAB. 1). De acordo com Chitarra e Chitarra (2005) época de semeadura, espaçamento, irrigação e proporções inadequadas de minerais durante o cultivo têm efeito adverso na qualidade final do produto, sendo, portanto, difícil identificar o efeito isolado de um fator.

O diâmetro das raízes foi significativamente influenciado pela época de colheita, sendo inferior nas raízes colhidas aos 83 DAS (FIG. 1A). Tal resultado já era esperado, pois o crescimento em diâmetro da raiz da cenoura se dá na fase final de seu desenvolvimento, semelhante ao que ocorre com a mandioquinha-salsa (MADEIRA, et al., 2008).

Houve diferença significativa do $\mathrm{pH}$ entre as épocas de colheita, com decréscimo proporcional ao adiamento da colheita (FIG. 1B). A significante diminuição do $\mathrm{pH}$ indica haver incremento na concentração de ácidos com o desenvolvimento das raízes.

A acidez titulável das raízes oscilou com a época de colheita (FIG. 1C). As raízes colhidas aos 107 DAS apresentaram acidez superior às demais épocas de colheita, corroborando com o resultado observado para o $\mathrm{pH}$ na última época de colheita. Resultados superiores foram detectados na cenoura 'Brasília', com acidez titulável de 2,49 e $2,01 \mathrm{mEq} / 100 \mathrm{~g}$ observados por Alves et al (2010) e Soares et al (2010), respectivamente.

$\mathrm{O}$ teor de vitamina $\mathrm{C}$ foi influenciado pela época de colheita das raízes de cenoura (FIG. 1D). Verificouse acréscimo no teor dessa vitamina durante o período de desenvolvimento das raízes. Valores superiores de vitamina C foram detectados em cenoura 'Brasília' por Soares et al (2010) de 14,95 mg/100 g, e na 'Nantes' por Lima et al. (2001) de $8 \mathrm{mg} / 100 \mathrm{~g}$. O incremento no conteúdo de vitamina $\mathrm{C}$ oscilou em $66 \%$, porém ainda foi baixa a concentração de vitamina $\mathrm{C}$ nas raízes de cenoura.

Tabela 1 - Análises físicas e físico-químicas das características massa fresca de raiz, comprimento, diâmetro, firmeza, sólidos solúveis, pH, acidez titulável e vitamina C de cenoura 'Brasília' em função do sistema de cultivo. Mossoró, 2009

\begin{tabular}{lrrr}
\hline \multirow{2}{*}{ Características } & \multicolumn{2}{c}{ Sistema de Cultivo } & \multirow{2}{*}{ C.V. (\%) } \\
\cline { 2 - 3 } & Consórcio & Monocultivo & 25,75 \\
\hline Massa Fresca (g) & $48,71 \mathrm{a}$ & $58,86 \mathrm{a}$ & 11,51 \\
Comprimento (cm) & $13,92 \mathrm{a}$ & $14,36 \mathrm{a}$ & 9,99 \\
Diâmetro (cm) & $2,61 \mathrm{~b}$ & $2,92 \mathrm{a}$ & 6,68 \\
Firmeza (N) & $159,62 \mathrm{a}$ & $166,68 \mathrm{a}$ & 12,50 \\
Sólidos Solúveis (\%) & $9,84 \mathrm{a}$ & $9,97 \mathrm{a}$ & 1,03 \\
pH & $6,23 \mathrm{a}$ & $6,26 \mathrm{a}$ & 24,21 \\
Acidez Titulável (mEq/100g) & $1,44 \mathrm{a}$ & $1,50 \mathrm{a}$ & 15,13 \\
Vitamina C (mg/100g) & $4,12 \mathrm{a}$ & $4,23 \mathrm{a}$ & \\
\hline
\end{tabular}

* Médias seguidas pela mesma letra não diferiram pelo teste de Tukey ao nível de significância de 5\% 

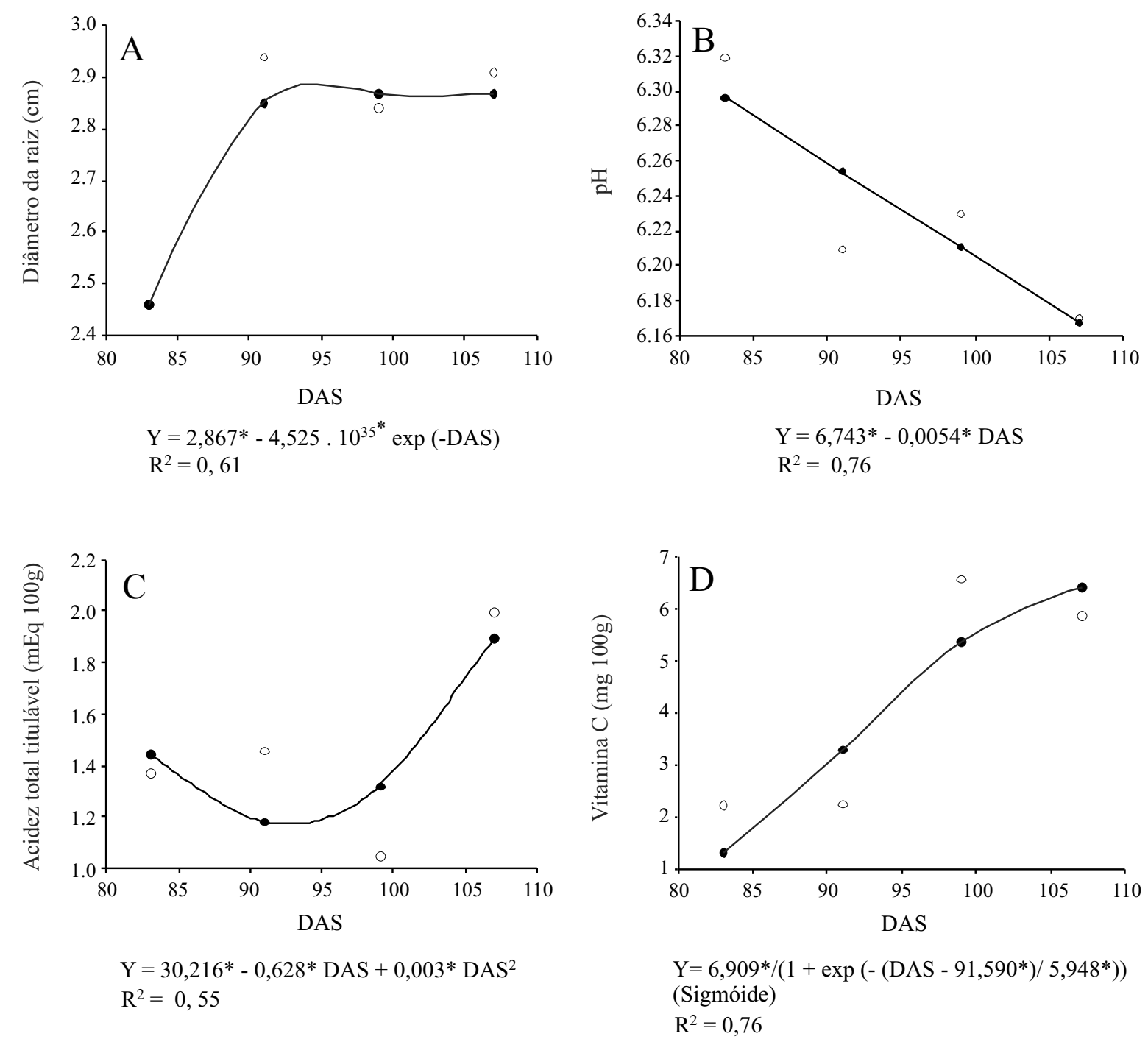

Figura 1 - Diâmetro da raiz (A), pH (B), acidez titulável (C) e vitamina C (D) de cenoura 'Brasília' em função das épocas de colheita. Mossoró, 2009. * Significativo pelo teste t de Student $(\mathrm{p}<0,05)$

O sistema de cultivo (TAB. 1) e época de colheita não influenciaram na massa fresca (FIG. 2A) e o comprimento de raízes de cenoura (FIG. 2B). Esse resultado se deve possivelmente ao ciclo curto de desenvolvimento do rabanete em relação ao da cenoura. Efeito contrário foi detectado para massa fresca em cultivo consorciado de alho e cenoura por Mueller et al. (2004). Os autores observaram que o sistema consorciado reduziu a massa de raízes de cenoura em relação ao sistema em monocultivo.

Resultado diferente foi observado por Pimentel et al. (2009). Os autores detectaram incremento no comprimento de raízes de cenoura consorciadas com alface em função do aumento da dose de composto orgânico. Os comprimentos das raízes variaram de 13 a $15 \mathrm{~cm}$ o que as classificam como pertencente à classe $10(10-14 \mathrm{~cm})$ e 14 (14-18 cm), (CEASA MINAS, 2009).

A firmeza das raízes e o teor de sólidos solúveis não foram influenciados pelo sistema de cultivo (TAB. 1) ou pelas épocas de colheita (FIG. 2C e 2D). Diferente destes resultados, Bezerra Neto et al. (2006) verificaram em cultivo consorciado de alface e cenoura, que a firmeza das raízes foi menor, quando a população de cenoura foi maior do que a de alface.

O teor médio de sólidos solúveis das raízes de $9,9 \%$, foi superior ao detectado por Alves et al (2010) em cenoura 'Brasília' (8,6\%). Apesar de constituir um fator que exerce influência no sabor do produto, esse não é um parâmetro importante na comercialização da cenoura. 

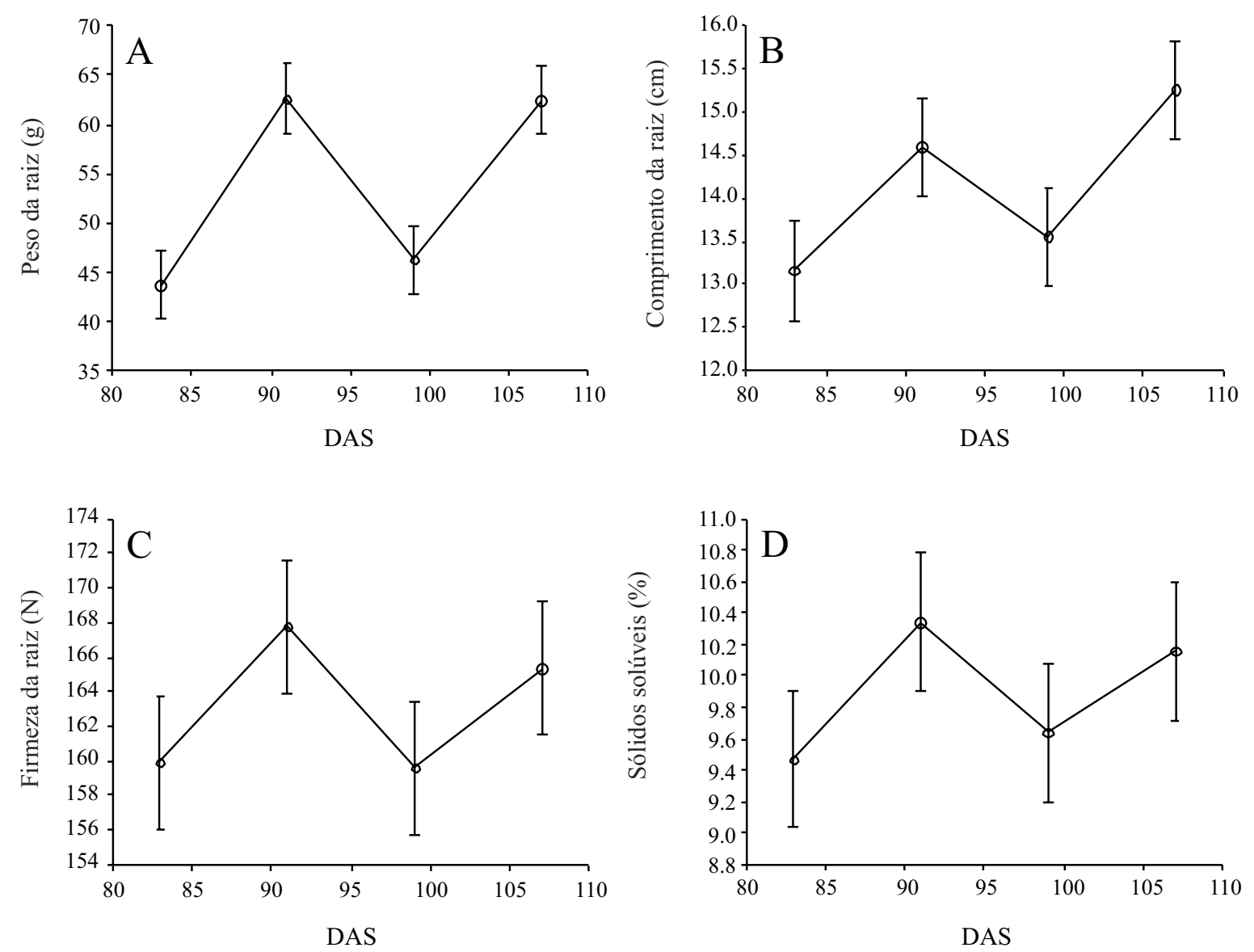

Figura 2 - Massa fresca de raíz (A), comprimento de raíz (B), firmeza de raíz (C) e sólidos solúveis de raíz (D) de cenoura 'Brasília' em função das épocas de colheita. Mossoró, 2009

\section{Conclusões}

1. O sistema de produção consorciado de cenoura e rabanete não proporcionou diferença nas características físicas e físico-químicas das raízes de cenouras, exceto para o diâmetro das raízes que foi menor em cultivo consorciado;

2. A época de colheita das raízes de cenoura influenciou o diâmetro, $\mathrm{pH}$, acidez titulável e vitamina $\mathrm{C}$. Com exceção do $\mathrm{pH}$ as demais características aumentaram com a época de colheita.

\section{Referências}

ALVES, S. S. V. et al. Qualidade de cenoura em diferentes densidades populacionais. Revista Ceres, v. 57, n. 02, p. 218-223, 2010.

BAARDSETH, P. et al. Evaluation of carrot varieties for production of deep-fried carrot chips. I Chemical Aspects.
Food Research International, v. 28, n. 01, p. 195-200, 1995.

BEZERRA NETO, F. et al. Análise multidimensional de consórcio cenoura-alface sob diferentes combinações de densidades populacionais. Pesquisa Agropecuária Brasileira, v. 42, n. 12, p. 1697-1704, 2007.

BEZERRA NETO, F. et al. Desempenho agroeconômico do consórcio cenoura $\mathrm{x}$ alface lisa em dois sistemas de cultivo em faixa. Horticultura Brasileira, v. 21, n. 04, p. 635-641, 2003.

BEZERRA NETO, F.et al. Qualidade nutricional de cenoura e alface cultivadas em Mossoró-RN em função da densidade populacional. Horticultura Brasileira, v. 24, n. 04, p. 476-480, 2006.

BRASIL. Ministério da Agricultura. Levantamento Exploratório: reconhecimento de solos do Estado do Rio Grande do Norte. s.l., DNPEA, SUDENE/USAID, 1971. (DPP. Boletim, 21PE13).

CARMO FILHO, F.; OLIVEIRA, O. F. Mossoró um município do semi-árido nordestino: características climáticas e aspectos florísticos. Mossoró: 1989. 62 p. (Coleção Mossoroense, 672. Série B). 
CEASA MINAS. Agroqualidade: cenoura. 2009. Disponível em: <http://www.ceasa minas.com.br/agroqualidade/cenoura. asp $>$. Acesso em: 15 jun. 2009.

CECÍLIO FILHO, A. B.; MAY, A. Produtividade das culturas de alface e rabanete em função da época de estabelecimento do consórcio. Horticultura Brasileira, v. 20, n. 03, p. 501-504, 2002.

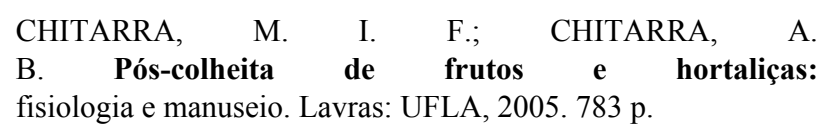

GRANGEIRO, L. C. et al. Crescimento e produtividade de coentro e rabanete em função da época de estabelecimento do consórcio. Ciência e Agrotecnologia, v. 32, n. 01, p. 55-60, 2008.

LIMA, K. S. C. et al. Efeito da irradiação ionizante $\gamma$ na qualidade pós-colheita de cenouras (Daucus carota L) cv. Nantes. Ciência e Tecnologia dos Alimentos, v. 21, n. 02, p. 202-208, 2001.

MADEIRA, N. R. et al. Mandioquinha-salsa (Arracacia xanthorrhiza). Brasília: Embrapa - CNPH, 2008. Disponível em: $<$ http://sistemasdeproducao.cnptia.embrapa.br/Fontes TML/ Mandioquinha/MandioquinhaSalsa/apresentacao.html > . Acesso em: 02 abr. 2009.

MONTEZANO, E. M.; PIEL, R. M. N. Sistemas de consórcio na produção de hortaliças. Revista Brasileira de Agrociência, v. 12 , n. 02 , p. 129-32, 2006.

MUELLER, S. et al. Épocas de consórcio de alho com cenoura em três sistemas de manejo de plantas daninhas, em CaçadorSC. Planta Daninha, v. 22, n. 04, p. 507-516, 2004.

NEGREIROS, M. Z. et al. Cultivares de alface em sistemas solteiro e consorciado com cenoura em Mossoró. Horticultura Brasileira, v. 20, n. 02, p. 162-166, 2002.
OLIVEIRA, E. Q. et al. Desempenho agroeconômico do bicultivo de alface em sistema solteiro e consorciado com cenoura. Horticultura Brasileira, v. 22, n. 04, p. 712-717, 2004.

PIMENTEL, M. S. et al. Rendimentos agronômicos em consórcio de alface e cenoura abubadas com doses crescentes de composto orgânico. Revista Ciência Agronômica, v. 40, n. 01, p.106-112, 2009.

REZENDE, B. L. A. et al. Análise econômica de cultivos consorciados de alface americana $\mathrm{x}$ rabanete: um estudo de caso. Horticultura Brasileira, v. 23, n. 03, p. 853-858, 2005.

REZENDE, F. V. et al. Uso de cobertura morta vegetal no controle da umidade e temperatura do solo, na incidência de plantas invasoras e na produção da cenoura em cultivo de verão. Ciência e Agrotecnologia, v. 29, n. 01, p. 100-105, 2005.

SISTEMA PARA ANÁLISES ESTATÍSTICAS (SAEG) Versão 9.0. Viçosa: Fundação Arthur Bernardes, 2005.

SALGADO, A. S. et al. Consórcios alface-cenoura e alfacerabanete sob manejo orgânico. Pesquisa Agropecuária Brasileira, v. 41, n. 07, p. 1141-1147, 2006.

SOARES, I. A. A. et al. Interferência das plantas daninhas sobre a produtividade e qualidade de cenoura. Planta Daninha, v. 28 , n. 02 , p. $247-254,2010$.

TEÓFILO, T. M. S. Crescimento de cultivares de cenoura nas condições de Mossoró-RN. Caatinga, v. 22, n. 01, p. 168-174, 2009.

VIEIRA, J. V. et al. Cultivo da cenoura. Brasília: Embrapa - CNPH, 2000. Disponível em: < http://www.cnph.embrapa.br/ sistprod/cenoura/index.htm >. Acesso em: 30 abr. 2009. 